\title{
Lazer Lipoliz Laser Lipolysis
}

\section{Cenk Akçalı, Perihan Öztürk*}

Gaziantep Üniversitesi Tıp Fakültesi, Deri ve Zührevi Hastalıklar Anabilim Dalı, Gaziantep, Türkiye *Kahranmanmaraș Sütçü İmam Üniversitesi Tıp Fakültesi, Deri ve Zührevi Hastalıklar Anabilim Dalı, Kahramanmaraș, Türkiye

\section{Özet}

Liposakșın klinik pratikte, en sık yapılan kozmetik cerrahi uygulamalardan birisidir. Son dönemlerde bu alanda kullanıma giren yardımcı yöntemlerden biri ise lazer lipoliz uygulamalarıdır. Bu teknik ile farklı dalga boylarındaki lazer enerjisi lipoliz ve hemostaz yaparken, neokollagenezi de stimüle etmektedir. Lazerin yağ dokuda kullanımı üzerine yapılmıș orijinal çalıșmalar gözden geçirilmiș ve değerlendirilmiștir. Bazı yazarlar lazer lipoliz uygulamasının genel anestezi altında yapılan geleneksel yöntemlere nazaran daha az yan etkili olduğunu öne sürmektedir. Ancak literatürde bu iki metodu objektif șekilde karșılaștıran çalıșma eksiği vardır. Lazer lipoliz tecrübelerinin artması, daha etkili ve güvenli tekniklere ulașmamızı sağlayacaktır. (Türkderm 2012; 46 Özel Sayı 1: 56-8)

Anahtar Kelimeler: Liposakșın, lazer lipoliz, kozmetik cerrahi

\section{Summary}

In clinical practice, liposuction is one of the most commonly performed cosmetic surgical procedure. Recently laser lipolysis is the latest adjunct procedure to liposuction. This technique employs laser energy with different wavelenghts to induce lipolysis and hemostasis and stimulate neocollagenesis. Original articles that studied the application of laser to adipose tissue were reviewed and included. Several authors claimed that laser lipolysis offers fewer side effects than traditional liposuction performed under general anesthesia. A true objective comparison within these two methods is missing in the literature. As laser lipolysis experience grows, it will help to achive more efficient and safer techniques. (Turkderm 2012; 46 Suppl 1: 56-8)

Key Words: Liposuction, laser lipolisis, cosmetic surgery

\section{Giriş}

Subkutan yağ dokusu ya da hipodermis, dermis ve altta yatan vücut dokusu arasında köprü görevi görür. Bu doku vücudun birçok alanında bu doku 1 kaç $\mathrm{mm}$ inceliğindeyken, bazı bölgelerde (kalça, abdomen, uyluk, dizler, üst kol, çene, yanaklar ve boyun) aşırı birikim gösterir. Liposakşın bu spesifik alanlardan istenmeyen yağların alınmasını tanımlayan bir prosedürdür? . Liposakşın ilk olarak 1980 yılında ABD'de kullanılmaya başlanmış olup, günümüzde oldukça sık uygulanan kozmetik işlemlerden birisidir. Birkaç farklı liposakşın tekniği bulunmaktadır. Tümesan anestezi tekniği ilk olarak Dr. Klein tarafından 1980'lerde tanımlanmış ve halende güvenle kullanılan bir tekniktir².

Tümesan anestezi tekniği sayesinde intraoperatif kanama riski ve kanamaya bağlı komplikasyonlar postoperatif ekimoz riski azalmıştır. Dermatolojik cerrahide kullanılan Klein solüsyonu; 1 litrelik normal salin solüsyonun içine 500-1000 mg lidokain $(\% 0,05-0,1)$, $1 \mathrm{mg}$ epinefrin (1:1000000 ünit) ve $12,5 \mathrm{ml}$ $\% 8,4$ lük sodyum bikarbonat eklenmesi ile oluşmaktadır ${ }^{3}$.

Strik tümesan tekniğinde ise intravenöz sedasyona gerek kalmadan sadece lokal anestezi ile liposakşın yapılmasına olanak sağlanmaktadır. Bu yöntemin kullanılmaya başlaması ile ciddi komplikasyon riski belirgin azalmıştı ${ }^{4}$.

Yazışma Adresi/Address for Correspondence: Dr. Cenk Akçalı, Gaziantep Üniversitesi Tıp Fakültesi, Deri ve Zührevi Hastallklar Anabilim Dall, Gaziantep, Türkiye

$$
\text { E-posta: cenkakcali@yahoo.com }
$$


Geleneksel liposakşında her ne kadar gelişmeler olsa da tekniğin belirgin kısıtlılıkları bulunmaktadır. Bunlar arasında postoperatif ödem ve ekimoz, doktor için yorucu olması ve özellikle fibröz yapılarda kontür düzenlenmesinin zor olması bulunmaktadır. Bu kısıtlıklıkları gidermek için ultrason destekli, güç destekli ve lazer destekli liposakşın geliştirilmiştir5.

\section{Tarihçe}

Illk olarak 1990'da Apfelberg lazer destekli liposakşını tanımlamıştır. Bu ön çalışmada liposakşın kanülü içine yttrium aluminium garnet (YAG) fiber optiği kullanıldı, fakat lazerin etkinliğinin olmadığı düşünülerek FDA tarafından onay verilmedi6. Daha sonraki çalışmacılar optik fiberli lazerin yağ dokuya direk teması ile yağ dokuda termal lizis oluştuğu, bu şekilde lazer destekli termal hasarın intraoperatif kan kaybını ve post operatif ekimozu azalttığı aynı zamanda da deride sıklaşma sağladığını gözlemlediler7-9. Bu olumlu gelişmeler lazer lipolize (LL) büyük bir ilgi duyulmasını sağlamıştır. NDYAG lazer (Smartlipo, Cynosure, Westfort, MA) yumuşak dokuda cerrahi insizyon, eksizyon, vaporizasyon, ablasyon ve koagülasyon için 2006 yılında FDA onayı almıştır5.

Günümüzde lazer destekli lipoliz ve LL için çok sayıda lazer geliştirilmiş olup artık lazerin yağ dokuya ulaşmasını sağlamak için küçük kanüller içinden geçen optik fiberler kullanılmaktadır³.

\section{Endikasyonları ve Kontrendikasyonları}

LL ve lazer destekli liposakşının başlıca endikasyonları vücut şekillendirmedir.

LL tek başına kullanılabildiği gibi geleneksel liposakşına yardımcı olarak ta kullanılabilir. LL ideal kilosunda ya da ideal kilosuna yakın olan kişilerde bölgesel yağlanmalarda en iyi sonucu verir. Bunun yanı sıra LL; lipom 10,11, jinekomasti12-14, aksiler hiperhidroz, malar bölgede intersitisyel sıvı poşları ve sellülit tedavi etmek içinde kullanılabilir5.

Hastanın beklentilerinin gerçekçi olmaması, gebelik ve laktasyon dönemi, lidokain alerjisi, uygulanacak anestezik işleme duyarlılık durumlarında LL uygulaması önerilmemektedir ${ }^{15}$.

LL'nin etkisi fototermal enerjiden kaynaklanmaktadır. Lazer ışığın enerjisi, yağ dokusunda, kollajen dokularda ve hemoglobinde ISI enerjisine dönüştürülmektedir. Farklı dalga boylarının yağ dokusu, su ve hemoglobin için farklı absorbsiyon katsayıları bulunmaktadır. Yağ dokusunda su oranı \%14 iken kollajen dokuda bu oran \%60-70'dir. Uygun lazer seçimi yağ doku ya da kollajenin hedef alınmasını sağlar (5). Bu amaçla farklı lazer sistemleri geliştirilmiştir.

\section{Lipolizde Kullanılan Lazerler}

\section{4-nm ND-YAG}

1064 nm lazerde doku penetrasyonun iyidir, daha az yağ absorbsiyonu nedeniyle ışık dağılır ve dokunun daha geniş ışınlanmasına olanak sağlar ${ }^{16}$. Bu dalga boyu oksihemoglobin tarafından absorbe edilir, bu sebeple de küçük damarları koagüle etmekte etkindir15. İnvitro olarak 1064nm Nd-YAG lazerin etkinliğini gösteren çalışmalarında Goldman ve Gotkin ${ }^{15}$ adiposit dokuya direk temas ile lipolizi ve beraberinde membran rüptürü, küçük damarlarda koagülasyon ve dermal ve subdermal yeni kollajen yapımını gösterdiler. Badin ve ark ${ }^{17}$ ise ilk defa invivo olarak 1 mm'lik ince kanüllerle 1064 nm Nd-YAG lazeri 245 hastada kullandılar. Çalışmalarında LL'nin geleneksel liposakşına oranla 1 mm'lik küçük kanüller kullanıldığı için daha az travmatik olduğunu göstermeyi amaçlamışlardı. Badin ve ark. çalışmalarında histolojik olarak kollajen bandlarının rüptürü, erimesi ve küçük damarların koagülasyonuna bağlı daha az kanama olduğunu gözlemlemişlerdir ${ }^{17}$. Goldman ve Badin'in yaptığı ön çalışmalardan sonra başka araştırmacılarda 1064 nm Nd-YAG lazerin etkinliğini farklı uygulamalarda değerlendirmişlerdir ${ }^{14,18-22}$. Ichikawa ve ark.7 1064 $\mathrm{nm} \mathrm{Nd}$-YAG lazerin insan derisindeki etkilerini elektron mikroskop altında incelemişlerdir. Taze alınmış insan derisine 100 is puls aralığında, $150 \mathrm{~mJ}$ ve 40 Hz'de 1064 nm Nd-YAG lazer uygulaması sonrasında elektron mikroskopik incelemede sıcak koagüle kollajen fiberler, dağılmış lipitler, dejenere hücre membranları ve yaklaşık 300 Im çaplı oyuklar gözlemlemişlerdir. Lazer uygulanmayan alanlarda ise adipositlerin görünümlerinin yuvarlak olduğu ve sönük olmadığı tespit edilmiştir.

Goldman ${ }^{19} 82$ hastanın submental alanına $40 \mathrm{~Hz}$ frekansta, $150 \mathrm{~mJ}$ enerjide 6 W güçte ve 100 ls puls aralığında 1064 nm Nd-YAG lazer uygulamış, uygulamadan hemen sonra ve 40. günde biyopsi yapmışıı. Kırkıncı gün yapılan biyopsi yerinde adipositlerde azalma ve neo vaskülarizasyon gözlemlenmiştir.

Kim ve Geronemus ${ }^{23}$ LL'nin yağ kaybı miktarını ölçmüşlerdir. Çalışmalarında 30 hastanın istenmeyen yağ içeren submental, üst kol ve kalçasını 1064 nm Nd-YAG lazerle tedavi etmişler, bu işlem sırasında normal lenfatik drenaja izin verdikleri için aspirasyon yapılmamış ve işlem sırasında ve işlemden 3 ay sonra 10 hastada manyetik resonans inceleme ile yağ miktarı ve doz yanıt eğrisi ölçülmüştür. İşlemden 3 ay sonrasında yapılan ölçümlerde yağ miktarında ortalama \%16'lık bir azalma gözlemlenmiştir.

$1320 \mathrm{~nm}$ lazerin su absorbsiyon katsayısı daha yüksektir ve yağ dokuda 1064 nm'ye göre daha daha fazla absorbe olurlar. Böylece çevreye daha az ısı tranferi sağlayarak boyun gibi derinin daha ince olduğu bölgelerde kullanıma olanak sağlarlar. Su absorbsiyon katsayısı yüksek olduğu için kollajeni de daha iyi ısıtır ${ }^{16}$. Bu iki dalga boylu lazer tek başlarına ya da kombine olarak kullanılabilmektedir.

Woodhall ve ark.24 yaptıkları pilot çalışmalarında tümesan teknik altında; bir kola 1064 nm Nd-YAG uygularken, diğer tarafın yarısına 1064 ve $1032 \mathrm{~nm}$ lazeri kombine diğer yarıya ise randomize olarak 1064 yada 1320 nm lazer uygulamışlardır. Çalışma sonucunda kombine lazerin diğer yöntemlerden çok daha etkili olduğunu bildirmişlerdir. Bir başka çalışmada McBean ve ark.25 1064 ve 1320 nm Nd-YAG lazer sisteminin kombine kullandıkları çalışmalarında 20 hastanın $\% 85$ 'inde \%76-100 oranında düzelme, \%15'inde ise \%51-76 oranında düzelme gözlemlediklerini bildirmişlerdir. Bu şekilde kombine uygulamanın lokalize yağ çıkarmada etkili ve güvenli bir yöntem olduğu bildirilmiştir.

\section{0, 924/975 nm Diod azerler}

Reynaud JE'nin26 980 nm diod lazerin etkinliği ve güvenilirliğini araştırmak için tümesan anestezi altında yaptığı 334 hastalık çalışmasında hastalarının \%80'inin memnun ya da çok memnun olduklarını bildirmiştir.

Mordon ve ark. $1064^{8} \mathrm{~nm}$ Nd-YAG ve $980 \mathrm{~nm}$ diod lazeri ex vivo ortamda histolojik olarak karşılaştırmasını yapmışlar ve iki lazerinde aynı güç ve maruziyet süresinde uygulanması durumunda histolojik değişimlerin benzer olduğunu bildirmişlerdir. Son zamanlarda FDA çift 
dalga boylu 924 ve 975 nm diod lazeri lazer destekli lipoliz için onaylamıştır. Her ne kadar çift dalga boylu diod lazer lipoliz için etkili gibi görünse de bu konuda yapılmış çalışma sayısı kısıtıdır³.

1064 nm Nd-YAG, 980 nm diod ve 1064/1320nm Nd-YAG lazer destekli lipolizde etkinliği ve güvenliği kanıtlanmış üç major lazer sitemi olarak kabul edilmektedir. Her birinin kendine ait avantajları vardır. 1064 nm Nd-YAG lazer güvenliği ve etkinliği uzun süreden beri bilinmektedir. Literatürde bu konu ile ilgili birçok bilgi bulunmaktadır. 980 nm diod lazer sürekli güç, yüksek güç ve emisyon gibi avantajlara sahiptir. Ayrıca diod lazer geniş alanlarda kullanım için uygundur1,27. 1064/1320 nm Nd-YAG lazer kombinasyonunda ise dermal kollajene karşı güçlü bir seçicilik ve neovaskülarizasyon sağlamak gibi avantajlara sahiptir. Böylece lokal yağlanmanın ve deri sarkmasının olduğu durumlarda bu lazerin kullanı Iması avantaj sağlar. Ayrıca 1320 $\mathrm{nm}$ lazer hemoglobini methemoglobine çevirir, $1064 \mathrm{~nm}$ lazer ise methemoglobin tarafından 3-5 kat daha fazla absorbe edilir, böylece hemostaz açısından sinerjistik etki gösterirler ve kanlanmanın çok olduğu yerlerde kullanılmaları idealdir¹.

\section{Lazer Uygulama Yöntemi}

Öncelikle LL yapılacak alan işaretlenir. Hastaya tümesan anestezi tekniği ile anestezi uygulanır. Kanüllerin gireceği yerlere küçük insizyonlar yapılır16. Operasyon alanındaki herkese lazerden korunmak amaçı gözlük takılmalıdır5.

Lazer yağ dokusuna bir optik fiber aracılığıyla uygulanır. Bu optik fiber tedavi amaçlı kızı ötesi dalga boylarında lazer ışınıyla birlikte klavuz olarak helyum neon ışı̆̆ını da taşır. Helyum neon ışığı transillüminasyonla dışardan görüldüğü için lazerin nerede olduğu takip edilebilir. Ayrıca bu fiber ucun parlaklığı ile lazerin derinlik seviyesi de ölçülebilir20.

Kayda değer tedavi sonuçları ancak aylar içinde ortaya çıkmaktadır.

\section{Komplikasyonları}

Lazer destekli lipoliz ve LL'e bağlı komplikasyonlar oldukça nadir gözlenmektedir. Enerji düzensiz ya da bir bölgeye yoğun uygulandığında termal hasarlar oluşabilir16,20.

Lokal komplikasyonlar; deri enfeksiyonu, deride kalıcı düzesizlik, deri ülseri ya da nekrozu, yapıştırılan banda bağlı alerjik kontak dermatit, kalıc şişlik ya da hipertrofik skar gibi lokal komplikasyonlar olabilir. Kullanılan sistemik ilaçlara bağlı allerjik reaksiyon, ateş, pulmoner

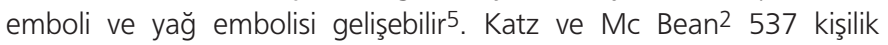
çalışmalarında hiçbir sistemik yan etkiye rastlamamışlar ve sadece 5 hastada lokal komplikasyonların geliştiğini bildirmişlerdir.

\section{Sonuç}

Lazer destekli lipolizle ilgili çok sayıda umut verici çalışma sonuçlar mevcuttur. Geleneksel liposakşın yerine lazer destekli liposakşının kullanılması hem komplikasyonları azaltmış hem de daha iyi kozmetik sonuçlar elde edilmesini sağlamıştır. Ancak termal hasar, ekipman maliyeti, uzun işlem süresi gibi kısıtlılıkarının olduğu da göz ardı edilemez.

Literatürde lazer destekli lipoliz ve LL'nin etkinliğini avantaj ve dezavantajlarını karşılaştıran oldukça kısıtlı sayıda çalışma mevcuttur. ilerleyen zamanlarda iki yöntemin ve kullanılan lazerlerin etkinlik ve yan etkilerini karşılaştıran geniş çalışmalara ihtiyaç vardır.

\section{Kaynaklar}

1. DiBernardo BE: Randomized, blinded split abdomen study evaluating skin shrinkage and skin tightening in laser-assisted liposuction versus liposuction control. Aesthet Surg J 2010;30:593-602.

2. Katz B, McBean J, Cheung JS: The new laser liposuction for men. Dermatol Ther 2007;20:448-51.

3. Fakhouri TM, El Tal AK, Abrou AE, Mehregan DA, Barone F: Laser-assisted lipolysis: a review. Dermatol Surg 2012;38:155-69.

4. Hanke W, Cox SE, Kuznets N, Coleman WP 3rd: Tumescent liposuction report performance measurement initiative: national survey results. Dermatol Surg 2004;30:967-77.

5. Tunca M, Erbil AH, Kurumlu Z: Lazerle deri altı yağ dokusunun giderilmesi. T Klin J Cosmet Dermatol 2009;2:61-5.

6. Apfelberg DB: Results of multicenter study of laser-assisted liposuction. Clin Plast Surg 1996;23:713-9.

7. Ichikawa K, Miyasaka M, Tanaka R, Tanino R: Histologic evaluation of the pulsed Nd:YAG laser for laser lipolysis. Lasers Surg Med 2005;36:43-6.

8. Mordon S, Eymard-Maurin AF, Wassmer B, Ringot J: Histologic evaluation of laser lipolysis: pulsed 1064-nm Nd: YAG laser versus cw 980-nm diode laser. Aesthet Surg J 2007:27:263-8.

9. Mordon SR, Wassmer B, Reynaud JP, Zemmouti J: Mathematical modeling of laser lipolysis. Biomed Eng Online 2008;7:10.

10. Stebbins WG, Hanke CW, Petersen J: Novel method of minimally invasive removal of large lipoma after laser lipolysis with $980 \mathrm{~nm}$ diode laser. Dermatol Ther 2011;24:125-30.

11. Saluja R: Dual-wavelength laser lipolysis treatment of lipomas: a case report. J Drugs Dermatol 2010;9:387-8.

12. Trelles MA, Mordon SR, Bonanad E, et al: Laser-assisted lipolysis in the treatment of gynecomastia: a prospective study in 28 patients. Lasers Med Sci 2012;19.

13. Wollina $U$, Goldman A: Minimally invasive esthetic procedures of the male breast. J Cosmet Dermatol 2011:10:150-5.

14. Rho YK, Kim BJ, Kim MN, Kang KS, Han HJ: Laser lipolysis with pulsed 1064 $\mathrm{nm} \mathrm{Nd}$ :YAG laser for the treatment of gynecomastia.Int J Dermatol 2009;48:1353-9.

15. Goldman A, Gotkin RH: Laser-assisted liposuction. Clin Plast Surg 2009;36:241-53.

16. Parlette EC, Kaminer ME: Laser-assisted liposuction: here's the skinny. Semin Cutan Med Surg 2008;27:259-63.

17. Badin AZ, Moraes LM, Gondek L, et al: Laser lipolysis: flaccidity under control. Aesthetic Plast Surg 2002;26:335-9.

18. Badin AZ, Gondek LB, Garcia MJ, et al: Analysis of laser lipolysis effects on human tissue samples obtained from liposuction. Aesthetic Plast Surg 2005;29:281-6.

19. Goldman A: Submental Nd:YAG laser-assisted liposuction.Lasers Surg Med 2006;38:181-4.

20. Goldman A, Gotkin RH, Sarnoff DS, et al: Cellulite: a new treatment approach combining subdermal Nd:YAG laser lipolysis and autologous fat transplantation. Aesthet Surg J 2008;28:656-62.

21. Dudelzak J, Hussain M, Goldberg DJ: Laser lipolysis of the arm, with and without suction aspiration: clinical and histologic changes. J Cosmet Laser Ther 2009;11:70-3.

22. Sun Y, Wu SF, Yan S, et al: Laser lipolysis used to treat localized adiposis: a preliminary report on experience with Asian patients. Aesthetic Plast Surg 2009:33:701-5.

23. Kim KH, Geronemus RG: Laser lipolysis using a novel 1064 nm Nd:YAG laser. Dermatol Surg 2006;32:241-8; discussion 47

24. Woodhall KE, Saluja R, Khoury J, Goldman MP: A comparison of three separate clinical studies evaluating the safety and efficacy of laser-assisted lipolysis using 1064, 1,320 nm, and a combined 1064/1,320 nm multiplex device. Lasers Surg Med 2009;41:774-8.

25. McBean JC, Katz BE: A pilot study of the efficacy of a 1064 and 1,320 nm sequentially firing Nd:YAG laser device for lipolysis and skin tightening. Lasers Surg Med 2009;41:779-84.

26. Reynaud JP, Skibinski M, Wassmer B, et al: Lipolysis using a 980-nm diode laser: a retrospective analysis of 534 procedures. Aesthetic Plast Surg 2009;33:28-36.

27. Sasaki GH: Quantification of human abdominal tissue tightening and contraction after component treatments with 1064-nm/1320-nm laserassisted lipolysis: clinical implications. Aesthet Surg J 2010;30:239-45. 